\title{
Predictive Validity of Critical Thinking Skills and Disposition for the National Board Dental Hygiene Examination: A Preliminary Investigation
}

\author{
Karen B. Williams, R.D.H., Ph.D.; Colleen Schmidt, R.D.H., M.S.; Terri S.I. Tilliss, R.D.H., \\ M.S., M.A.; Kris Wilkins, R.D.H., M.S.; Douglas R. Glasnapp, Ph.D.
}

Abstract: The objective of this study was to determine if preexisting critical thinking skills and critical thinking disposition predict student performance on the National Board Dental Hygiene Examination (NBDHE). The predictive value of critical thinking skills scores and disposition (habits of mind, attitudes, and character attributes) scores were examined above that provided by traditional predictors: entering grade point average, age, and total number of college hours at entry into the dental hygiene program. Seventy-six first-year dental hygiene students from three baccalaureate dental hygiene programs participated in this study. Participants' preexisting general critical thinking skills and disposition were assessed during the first week of classes in their respective baccalaureate level programs using the California Critical Thinking Skills Test (CCTST) and California Critical Thinking Disposition Inventory (CCTDI). At the completion of their two-year educational program, the CCTST and CCTDI were administered a final time, and students' scores on the multiple-choice and case-based NBDHE were obtained. A series of hierarchical multiple regression analyses demonstrated that CCTST scores explained a statistically significant $(\mathrm{p}<.05)$ proportion of variance in students' multiple-choice and case-based NBDHE scores, above and beyond that explained by other predictor variables. Although CCTDI scores were not a significant predictor of either outcome measure, CCTST is a good predictor of student performance on high-stakes qualifying examinations and may have utility for student selection and retention.

Dr. Williams is Professor, Department of Dental Public Health and Behavioral Science, University of Missouri-Kansas City; Ms. Schmidt is Director of Education, American Dental Hygienists' Association, Chicago; Prof. Tilliss is Associate Professor, Department of Dental Hygiene, University of Colorado; Prof. Wilkins is Chair, Department of Dental Hygiene, Loma Linda University; and Dr. Glasnapp is Professor, Department of Education, University of Kansas. Direct correspondence and requests for reprints to Dr. Karen Williams, University of Missouri-Kansas City School of Dentistry, 650 E. $25^{\text {th }}$ Street, Kansas City, MO 64108; 816-235-2058 phone; williamsk@umkc.edu.

Key words: critical thinking, clinical reasoning, National Board Dental Hygiene Examination, predictive validity

Submitted for publication 10/26/05; accepted 1/23/06

$\mathrm{L}$ eaders in dental education continue to emphasize the importance of developing critical thinking skills in allied dental students. ${ }^{1-3}$ Traditionally, allied dental education has relied on a teacher-delivered, lecture-based educational approach along with a performance-based approach to clinical activities. ${ }^{4}$ Several authors have suggested that these educational strategies result in discrete, isolated knowledge and performance, while not encouraging the application of critical thinking to the clinical environment. ${ }^{4-11}$ Application of critical thinking in clinical care is termed clinical reasoning.

Clinical reasoning is characterized as a complex and often unconscious integration of critical thinking and data-collecting procedures aimed at patient care. ${ }^{12-15}$ Critical thinking is subsumed in clinical reasoning in that clinicians must analyze information, use inductive and deductive reasoning to generate hypotheses about diagnoses, establish and prioritize patient care plans, make inferences, and reach conclusions on the basis of available information in order to increase the probability of a desirable outcome..$^{12,13,15-19}$ The inherent skills required for clinical reasoning include the ability to sort information, select key elements within that information, and search for and/or recognize relevant patterns..$^{20,21}$ Groves et al. demonstrated that content-specific knowledge and the ability to collect meaningful data increase with experience, whereas incorrect data interpretation does not. These authors hypothesize that confirmation bias resulting from past clinical experience may restrict the reasoning ability of experienced clinicians. ${ }^{21}$ Confirmation bias is an individual's tendency to interpret information in a way that confirms one's preconceptions. Several researchers have also suggested that pattern recogni- 
tion and organization of information are necessary for creating accurate and elaborate structures of knowledge required to manage patients. ${ }^{22-25}$ While allied dental education does focus on teaching students a methodical process for approaching patient care (termed the "dental hygiene process of care"), there is little evidence that learning this process translates into enhanced clinical reasoning skills. ${ }^{12,13}$ Dental hygiene clinicians routinely make decisions about patient care under conditions of uncertainty. For example, synthesizing an appropriate dental hygiene treatment and evaluation plan for a patient with an impaired self-care ability but complex oral needs requires the ability to make logical determinations about the potential success of various strategies.

Several authors have suggested that health professions students' preexisting critical thinking (CT) skills may have utility as a predictor of clinical performance. Additionally, some have proposed that assessing CT skills of health professions students may serve as an effective screening mechanism to identify immature critical thinking ability in order to develop educational strategies for these individuals after admission to academic programs. ${ }^{17,26-35} \mathrm{~A}$ recent study examined the predictive utility of critical thinking skills on early clinical decision making in allied dental education. ${ }^{36}$ Results reported on 207 students from seven baccalaureate-level dental hygiene programs showed that critical thinking skill, as measured by the California Critical Thinking Skills Test (CCTST), was a statistically significant predictor of early clinical reasoning ability. Moreover, the CCTST was a stronger predictor of early clinical reasoning than the traditional predictors of entering grade point average (GPA), number of college hours completed at entry into the program, and the student's age. Other studies have also shown that traditional admissions criteria such as standardized tests, total GPA, and science GPA often poorly correlate with measures of clinical judgment and performance in patient care tasks. ${ }^{29-33,35,37,38}$ Because of these limitations, there has been increasing interest in assessing other measures as predictors of student ability and achievement. Findings across different age groups and academic disciplines suggest that metacognitive measures such as motivation, maturity, disposition, and other affective measures may also have utility in predicting student performance. ${ }^{39-42}$

Although there appears to be a general consensus that direct instruction in teaching critical thinking is necessary to enhance clinical reasoning, there is an inherent problem with this solution. The rapid increase in scientific and health-related information in the health professions has already created overloaded curricula. Increasing the time necessary to teach critical thinking will add considerable stress to an already time-constrained curriculum. Additionally, there is still some confusion about how best to teach and evaluate critical thinking and clinical reasoning skills. ${ }^{42-44}$ Tanner et al. cite two significant problems: first, teaching clinical reasoning takes a great deal of time before change is observable; and second, there are limited outcome measures with acceptable psychometric properties for assessing change in $\mathrm{CT}^{43}$

Further, while the concept of critical thinking is widely embraced in education, there is little agreement on its operational definition and most appropriate means for measuring it. Several existing measures (Watson Glaser Critical Thinking Appraisal instrument and the Cornell Critical Thinking test) have been criticized for being narrow in scope, lacking a component that assesses disposition, or not meeting the Standards for Educational and Psychological Testing. ${ }^{14,19,30,45}$

The Delphi Research project on critical thinking (American Philosophical Association, 1990) gave researchers the first cross-disciplinary conceptual definition of general critical thinking. ${ }^{42,46}$ Fortysix theoreticians from the United States and Canada representing several academic fields comprised the panel of experts who generated a consensus definition of critical thinking. This definition embraced a wider range of criteria while still being compatible with previous definitions in the critical thinking literature. The Delphi panel also characterized the core set of general critical thinking skills and attitudes on which the California Critical Thinking Skills and Disposition inventories were based. Additionally, faculty need to better understand the premises underlying critical thinking and need guidance in methods for fostering good clinical judgment. ${ }^{33,46,47}$ Behar-Horenstein et al. showed that dental faculty rely primarily on teacher-dominated instruction or coaching techniques such as questioning and hypothesis generation to foster critical thinking skills and do so only 2.2 percent of the time in the clinical environment. ${ }^{47}$

Literature from various health professions suggests that students' existing critical thinking ability may be an important predictor of success and clinical judgment. ${ }^{48}$ Given that sufficient time and teaching strategies are not always available to effectively teach critical thinking skills/clinical reasoning skills after 
students enroll in an academic program, an alternative is to require that students possess these skills at a sufficient level upon entry into the program. However, there is a need to establish the utility of such measures as predictors and provide evidence to support their use. To date, no research has examined the predictive validity of critical thinking skills and a disposition for critical thinking for traditional outcomes in dental hygiene education. Therefore, the purpose of this study was to determine the predictive validity of critical thinking skills and critical thinking disposition for National Board Dental Hygiene Examination Scores (NBDHE) in a sample of dental hygiene students from three baccalaureate programs.

\section{Methods}

A convenience sample of baccalaureate-level, dental hygiene students from three dental hygiene programs $(\mathrm{N}=78)$ participated in this study. Institutions were selected based on their willingness to participate in the study, and student volunteers were offered the opportunity to participate during their first week of entry into their respective dental hygiene programs. The three participating institutions were the University of Colorado Health Sciences Center, the University of Missouri-Kansas City, and Loma Linda University. Students from baccalaureate dental hygiene programs housed within dental schools were selected to control for potential confounding variables of different curricula and preprofessional education. ${ }^{14,27,49}$ Institutional Review Board approval was obtained from the participating institutions. There were no incentives offered to students for participating; however, a pizza party was given at the completion of the study at each institution.

A site coordinator was recruited from each institution to ensure standardization of procedures throughout the study. Site coordinators met for a twoday calibration and training session on study implementation and administration of critical thinking measures to reduce variation in study procedures between sites.

The California Critical Thinking Skills Test (CCTST) and the California Critical Thinking Dispositions Inventory (CCTDI) were administered to participants during the first week of their entry into the dental hygiene program and again at the completion of their two-year educational program. Total scores for each of the measures were computed for the two separate administrations. The CCTST and
CCTDI are both standardized, norm-referenced tests that assess the context-general critical thinking skills and core critical thinking dispositions. ${ }^{50,51}$ Both have been shown to be psychometrically sound instruments. The CCTST reports a total score based on analysis, inference, evaluation, inductive reasoning, and deductive reasoning. The California Critical Thinking Disposition Inventory (CCTDI) assesses seven dispositional constructs: inquisitiveness, systematicity, analyticity, truth-seeking, openmindedness, self-confidence, and maturity.

Program directors provided the following data for each participant: entering GPA, total college hours at entry, students' age at entry, initial and final CCTST and CCTDI scores, and NBDHE scores for the Multiple-Choice Component (NBDHE MC) and CaseBased Component (NBDHE CB). Data were coded to ensure anonymity while concomitantly allowing for matching of data.

Several analyses were used to examine the data. Descriptive analyses characterized baseline data for students at each of the participating institutions. Correlations among predictor variables and NBDHE component scores were examined to determine the degree of relationship among measures.

To assess the primary research question- "To what degree do students' preexisting critical thinking skills and disposition uniquely predict performance on the NBDHE"-a series of hierarchical multiple regression analyses were used to examine the variance explained by the CCTST and CCTDI beyond that explained by traditional measures of incoming GPA, age, and total college credit hours. The hierarchical structure utilized in the regression analyses forced the dummy-coded institution variable into the model first to effectively control for the potential confounding effect of different curricula and coursework among the institutions. Part $\mathrm{r}^{2}$ coefficients were then computed to allow for the examination of unique variance explained by the effects of the traditional predictors and CCTST and CCTDI.

\section{Results}

Baseline data on age, entering GPA, and number of college credit hours at program entry, along with CCTST and CCTDI total scores are displayed in Table 1. Overall, participants ranged in age from nineteen to fifty-five with an overall mean age of 25.4 ( \pm 6.3 ). Participants' mean ages were comparable among institutions. Entering GPA for all par- 
Table 1. Distribution of predictor and criterion measures by institution

\begin{tabular}{|c|c|c|c|c|c|c|c|c|c|c|}
\hline Institution & & Age & GPA & Hours & $\begin{array}{l}\text { CCTST } \\
\text { Initial }\end{array}$ & $\begin{array}{l}\text { CCTDI } \\
\text { Initial }\end{array}$ & $\begin{array}{c}\text { CCTST } \\
\text { Final }\end{array}$ & $\begin{array}{l}\text { CCTDI } \\
\text { Final }\end{array}$ & $\begin{array}{c}\text { NBDHE } \\
\text { MC }\end{array}$ & $\begin{array}{c}\text { NBDHE } \\
\text { CB }\end{array}$ \\
\hline \multirow{2}{*}{$\begin{array}{l}\text { Institution } 1 \\
n=20\end{array}$} & Mean & 25.6 & 3.42 & 89.3 & 15.1 & 303.2 & 16.1 & 297.5 & 88.8 & 99.2 \\
\hline & S.D. & 5.7 & 0.35 & 31.2 & 3.6 & 31.0 & 3.2 & 32.8 & 4.2 & 7.8 \\
\hline \multirow{2}{*}{$\begin{array}{l}\text { Institution } 2 \\
n=34\end{array}$} & Mean & 25.0 & 3.33 & 73.1 & 15.0 & 293.0 & 16.1 & 281.5 & 84.3 & 91.0 \\
\hline & S.D. & 5.8 & 0.31 & 33.9 & 4.0 & 25.8 & 4.6 & 23.8 & 5.0 & 10.4 \\
\hline \multirow{2}{*}{$\begin{array}{l}\text { Institution } 3 \\
n=22\end{array}$} & Mean & 25.8 & 3.13 & 79.9 & 14.5 & 315.1 & 13.0 & 312.8 & 83.5 & 96.0 \\
\hline & S.D. & 7.7 & 0.38 & 20.3 & 5.0 & 23.8 & 4.6 & 28.0 & 3.5 & 8.4 \\
\hline \multirow[t]{2}{*}{ All Participants } & Mean & 25.4 & 3.30 & 79.3 & 14.9 & 302.1 & 15.1 & 295.4 & 85.2 & 94.6 \\
\hline & S.D. & 6.3 & 0.35 & 30.2 & 4.2 & 28.0 & 4.4 & 30.4 & 4.8 & 9.8 \\
\hline
\end{tabular}

ticipants ranged from 2.02 to 3.96 , with an overall mean GPA of $3.30( \pm 0.35)$. Entering mean GPA was similar among institutions and ranged from 3.13 to 3.42. With respect to the number of college credit hours at entry into the dental hygiene programs, the mean number of entering college credit hours for all participating students was $79.3( \pm 30.2)$. The large standard deviations for all institutions demonstrate a wide variability of students' academic preparation prior to entry into dental hygiene, irrespective of institutional affiliation.

The baseline CCTST score for the sample was $14.9( \pm 4.2)$. Overall, mean scores for participants at each institution were comparable, ranging from 14.5 to 15.1. Scores for the final administration of the CCTST were similar to those obtained at baseline. The CCTDI baseline scores for all subjects ranged from 241.0 to 367.0 , with an overall mean score of $302.1( \pm 28.0)$. Institution-level CCTDI scores for subjects ranged from 293.0 to 315.1. Scores for the final administration of the CCTDI were slightly lower than initial scores across all institutions, but the differences across the two-year time frame are well within the range of normal variability.

National Board Dental Hygiene Examination (NBDHE) scores were obtained for students at each participating institution. The overall mean scores for participants on the multiple-choice and case-based components were 85.2 and 94.6, respectively. Although the NBDHE scores were similar across the three institutions, Institution 1 had slightly higher scores for both components.

Correlations among predictor and criterion variables, displayed in Table 2, show that bivariate correlations varied in strength and direction. The majority of correlations between predictor variables were weak and nonsignificant; however, the relationship between number of college hours completed and age was statistically significant $(\mathrm{r}=.316)$, as was the correlation between initial CCTDI and CCTST scores ( $r=.291)$. Additionally, the relationships between the initial and final administrations

Table 2. Correlation among predictor and criterion variables

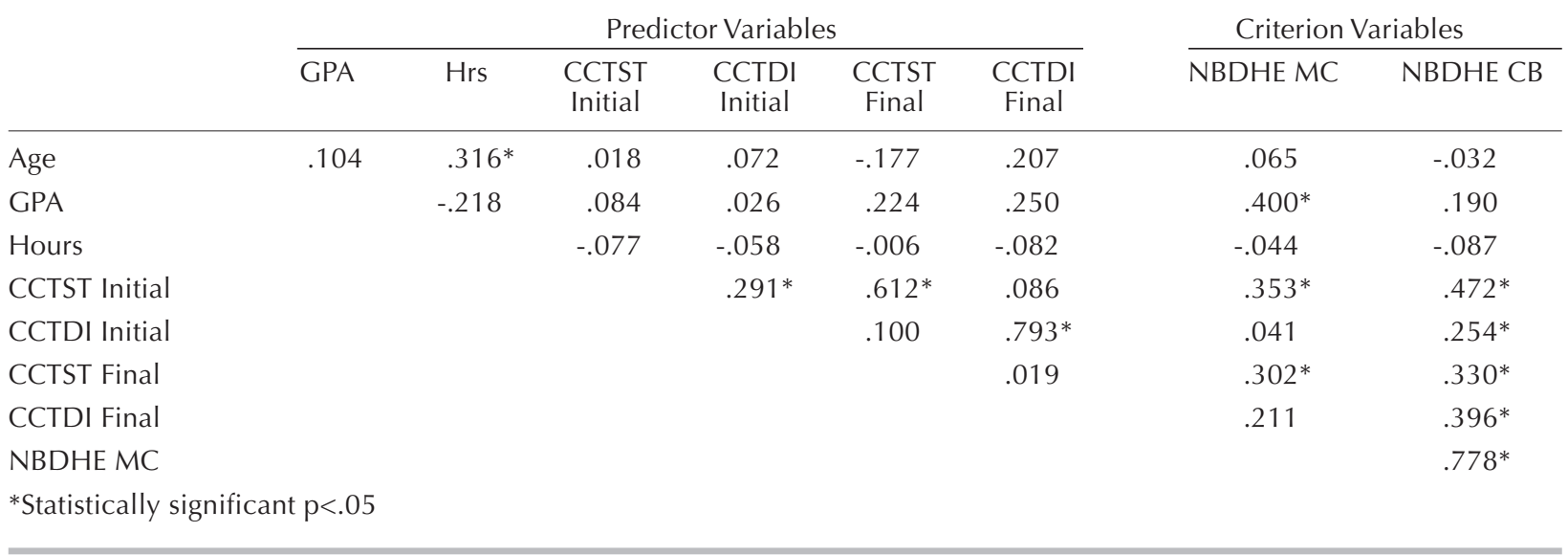


Table 3. Regression model: relationship of predictor variables to NBDHE MC scores

\begin{tabular}{lcccc} 
Variables in the Model & Model R & $R^{2}$ Change & F Change & p \\
\hline Institution & .443 & .196 & 8.90 & .0001 \\
Institution, Age, GPA, Credit Hours & .542 & .098 & 3.24 & .027 \\
Institution, Age, GPA, Credit Hours, CCTDI & .542 & .000 & .022 & .883 \\
Institution, Age, GPA, Credit Hours, CCTDI, CCTST & .632 & .105 & 11.94 & .001 \\
\hline
\end{tabular}

Table 4. Unique variance in NBDHE MC scores by predictive measures

\begin{tabular}{lll} 
Predictor Variable & Part $\mathrm{r}^{2}$ & $\mathrm{p}$ value \\
\hline Institution & .129 & .001 \\
Age, GPA, Credit Hours & .087 & .026 \\
CCTST & .105 & .001 \\
CCTDI & .008 & .352 \\
\hline
\end{tabular}

of the CCTST and CCTDI were fairly strong at $\mathrm{r}=.612$ and .793 , respectively. These values suggest that these critical thinking constructs are relatively stable across the two-year academic program period. The relationship between initial CCTST scores and NBDHE component scores was stronger for the case-based component $(\mathrm{r}=.472)$ than for the multiple-choice component ( $\mathrm{r}=.353)$. Not surprisingly, the relationship between NBDHE component scores was high, with $\mathrm{r}=.778$.

Descriptive data suggested several preliminary analyses were appropriate to examine the degree to which relationships among measures might attenuate or otherwise affect examination of the primary hypotheses. A primary assumption underlying critical thinking skills and disposition is that these constructs are largely unaffected by traditional curricular courses, but do tend to increase as a function of general education and/or a specific logic course. ${ }^{18,44,45}$ Therefore, separate regression analyses were used to examine the contribution of scores from the final administration of the CCTST when entered last in the model for each outcome measure while controlling for institution and initial CCTST scores. Similarly, the final administration of the CCTDI was modeled in the same manner. These results showed that the final administration of the critical thinking measures had a very small effect on the criterion measures, with $\mathrm{R}^{2}$ change values ranging from .005 to .022 . Based on these results, the final administration of the CCTST and CCTDI was eliminated from subsequent regression models.
Descriptive data identified institutional differences on the two criterion measures; therefore, a series of regression analyses were performed to determine the degree to which the differential effect of institution with predictor variables influenced each of the criterion measures. For each analysis, the predictor variable was entered first into the regression model followed by the dummy-coded institution variable. Cross-product variables between predictor and institution were entered last to test for the equality of slopes in the prediction equations across institutions. Regression line slopes for the three institutions were found to be comparable when modeling the predictors' relationship with NBDHE multiple-choice (NBDHE MC) and NBDHE case-based (NBDHE $\mathrm{CB})$ examinations.

To evaluate the primary research question regarding the predictive validity of CCTST and CCTDI, a series of hierarchical multiple regression analyses were conducted to examine the explained variance contributed by the baseline critical thinking measures (CCTST and CCTDI) beyond that explained by traditional measures of incoming GPA, age, and total college credit hours. In each model, institution was entered in the first step to control for potential differences in curricular content. Improvement in each model was determined based on the $\mathrm{R}^{2}$ change and significance for each step.

Table 3 displays the model regressing NBDHE $\mathrm{MC}$ component scores on institutional affiliation, traditional predictor variables, and initial critical thinking variables. Results suggest that institution affiliation explained the largest proportion of variance $\left(\mathrm{R}^{2}\right.$ change $=.196)$ in the criterion measure. CCTST was a statistically significant predictor $\left(\mathrm{R}^{2}\right.$ change $\left.=.105\right)$, as were traditional predictors (age, GPA, and number of college hours completed). Traditional predictors collectively explained 9.8 percent of variance in NBDHE MC scores. The contribution of initial CCTDI was not meaningful $\left(\mathrm{R}^{2}\right.$ change $\left.=.00\right)$. The unique proportion of variance in NBDHE MC component scores explained by each of the predictors $\left(\right.$ Part $^{2}{ }^{2}$ ) is shown in Table 4. In order of contribution, institutional af- 
Table 5. Regression model: relationship of predictor variables to NBDHE CB component scores

\begin{tabular}{lcccc} 
Variables in the Model & Model R & R $^{2}$ Change & F Change & Sig \\
\hline Institution & .363 & .132 & 5.55 & .006 \\
Institution, Age, GPA, Credit Hours & .430 & .053 & 1.53 & .215 \\
Institution, Age, GPA, Credit Hours, CCTDI & .458 & .024 & 2.14 & .148 \\
Institution, Age, GPA, Credit Hours, CCTDI, CCTST & .628 & .184 & 20.66 & .0001 \\
\hline
\end{tabular}

filiation was the single largest predictor, with CCTST ranking second, and traditional predictors explaining the least amount of variance.

Linear regression modeling of the relationship of CCTST and CCTDI to NBDHE CB component scores is displayed in Table 5. As with the NBDHE $\mathrm{MC}$ component scores, these results demonstrate a statistically significant effect of institution on NBDHE CB of students $\left(\mathrm{R}^{2}=.132\right)$. A small and nonsignificant increase in explained variance was noted for traditional variables $\left(\mathrm{R}^{2}\right.$ change $\left.=.053\right)$, whereas CCTST scores explained 18.4 percent of variance in the outcome measure ( $\mathrm{p}=.0001)$. CCTDI did not contribute a significant proportion of variance in NBDHE CB $\left(\mathrm{R}^{2}\right.$ change $\left.=.024\right)$. Overall, the proportion of variance accounted for in NBDHE CB scores for this model was 39.4 percent.

Summary data for the unique variance (Part $\left.\mathrm{r}^{2}\right)$ accounted for by institutional affiliation, traditional predictors and critical thinking variables for this model are displayed in Table 6. The unique variance explained by the baseline CCTST was the largest contributor to NBDHE CB component scores (Part $\mathrm{r}^{2}=.184$ ). Institutional affiliation predicted the next largest amount of unique variance (Part $\mathrm{r}^{2}=.132$ ). Traditional predictors (GPA, number of college hours at entry, and student age) were not statistically significant, nor was CCTDI, in predicting student performance on the case-based portion of the NBDHE.

\section{Discussion}

\section{Critical Thinking Measures as Predictors}

The primary purpose of this investigation was to examine the predictive validity of two critical thinking measures on National Board Dental Hygiene Examination component scores: the multiple-choice, knowledge-based component and the clinical, casebased component. Results of this investigation sug-

\begin{tabular}{|c|c|c|}
\hline Predictor Variable & Part $r^{2}$ & $\mathrm{p}$ value \\
\hline Institution & .129 & .001 \\
\hline Age, GPA, Credit Hours & .036 & .269 \\
\hline CCTST & .184 & .0001 \\
\hline CCTDI & .000 & .889 \\
\hline
\end{tabular}

gest that preexisting critical thinking skill, as measured by the CCTST, was a more consistent predictor of student performance on both the NBDHE MC and NBDHE CB scores than traditional predictors (age, GPA, and number of college hours at entry into dental hygiene). Additionally, the low correlations between CCTST and CCTDI, entering GPA, and number of college hours suggest that these constructs are different from traditional measures of academic achievement. These results are consistent with our previous study that showed CCTST had predictive validity in predicting students' early clinical performance. ${ }^{36}$ As with the previous study, institutional affiliation of the students was a predictor of student examination performance for both components. It is probable that differences among institutions with respect to student selection criteria, course content, and faculty and student characteristics were collectively responsible for the large proportion of variance explained in NBDHE performance.

A surprising finding was that CCTST was the single best predictor of performance on the casebased component of NBDHE. This suggests that students' context-general ability to reason has utility in predicting their context-specific clinical reasoning as measured by the case-based component of the NBDHE. These results are consistent with previous studies that have demonstrated the general critical thinking ability to sort information, search for patterns, and select key features is necessary in the clinical reasoning process. ${ }^{26,29,32,52}$ The NBDHE is a highly standardized and validated examination that requires candidates to review medical/dental history, radio- 
graphic, and clinical data; select key features in the data; work through logical hypotheses related to the case; and then determine appropriate dental hygiene care. This clinical reasoning process can be framed as the application of context-general thinking skills to context-specific patient cases.

The utility of context-general skills in contextspecific patient care has been an area of interest in numerous health professions over the past two decades. Although some studies have failed to find a significant relationship between critical thinking and clinical reasoning, ${ }^{52-54}$ other findings are consistent with our results. ${ }^{19,24,25,28,34,42}$ Studies failing to show a relationship between critical thinking and clinical reasoning, in general, have employed a single and subjective measure of clinical reasoning. In contrast, studies showing a link between the context-general skills and applied clinical reasoning have employed measures with established psychometric qualities (validity and reliability) and frequently have used multiple outcome measures to enhance generalizability of results.

Critical thinking and clinical reasoning are clearly complex constructs that require multiple abilities. Errors related to any of these abilities have the potential to negatively affect decision making. Groves et al. showed that the most common errors made in clinical reasoning included inadequate identification of relevant information, poor interpretation of data, and/or flaws in hypothesis generation. ${ }^{21}$ Groves et al., along with other authors, suggest that this might result in poor pattern recognition and an impaired thinking framework or organizational ability. ${ }^{21,25}$ Moreover, Brailovsky et al. demonstrated that students who possess the ability to organize clinical information early in their training go on to develop good clinical reasoning skills. ${ }^{42}$ Collectively, the literature suggests that preexisting skills in general critical thinking may predispose individuals to better clinical reasoning skills.

A primary goal of allied dental education is to produce clinicians with the ethics, skills, and knowledge to provide optimum and individualized oral health care. Thus, it seems logical that entry qualifications for these programs should include a variety of measures aimed at capturing the skills needed to produce effective clinicians. From a practical perspective, one might argue that the overall contribution of CCTST to predicting NBDHE scores was only moderate. However, critical thinking skills did show utility in predicting case-based outcomes that ex- ceeded all other covariates, including traditional entry criteria.

The cost-benefit balance of using the CCTST as an admission criterion was not considered in this investigation, nor was the predictive validity of CCTST on clinical competency as measured by regional and state qualifying examinations. It is anticipated that the characteristics of students seeking admission into dental hygiene will change as career opportunities either increase or decrease. Tracking the cognitive and affective critical thinking attributes of successive classes might also assist educators in selecting and/or meeting the needs of student populations as they change.

It should be cautioned that these preliminary results were obtained from a small sample of students who were enrolled in baccalaureate-granting dental hygiene programs. Clearly, there is a need for additional studies on larger and more varied student populations. There remains a need for both quantitative and qualitative research to further clarify the mechanisms by which critical thinking is related to clinical reasoning, as well as to determine how best to develop clinical reasoning skills of students for all educational program types. In nursing and occupational therapy, qualitative research has been used to examine decision making and clinical judgment skills of students and of inexperienced and experienced clinicians. ${ }^{55-62}$ In general, these studies have clarified the mental processes used to arrive at clinical decisions and suggest that processes become more refined and rapid with experience. Similar studies in dental hygiene and dental education would help elucidate how critical thinking and clinical reasoning processes continue to develop and be refined as clinicians move from competency to proficiency to mastery. This in turn could enhance the pedagogical processes in allied dental and dental education.

\section{Conclusions}

Results from the current investigation suggest that critical thinking skills, as measured by the CCTST, explain a statistically significant proportion of variance in the multiple-choice and case-based component scores of the NBDHE. Additionally, the degree to which CCTST explains variance in the outcomes exceeded that predicted by entering GPA, number of college hours, and the student's age. The CCTST was especially effective as a predictor of the 
case-based portion of the NBDHE. Critical thinking disposition (CCTDI) was not valuable as a predictor of board examination scores. With the current emphasis on educating students who are capable of good clinical reasoning in allied dental and dental education, coupled with the early evidence that faculty do little to teach clinical reasoning, ${ }^{57}$ continued research in this area is warranted. This may have implications for student selection and retention, faculty development, and pedagogical practices. As dental educators improve their understanding of how students develop clinical reasoning skills, the learning environment can be modified to foster growth in these areas. Pedagogical practices that facilitate the development of critical thinking and clinical reasoning skills can then be implemented and evaluated.

\section{Acknowledgments}

We thank the ADHA Institute for Oral Health and ADEA/Young Dental Manufacturing Company Dental Hygiene Development Grant for funding. We also thank John Poggio, Ph.D., Janet Marquis, Ph.D., Pamela Duncan, P.T., Ph.D., Daniel Tira, Ph.D., William Mayberry, Ph.D., and the late Nona Tollefson, Ph.D., for their advice and support on the development of this project.

\section{REFERENCES}

1. DePaola D, Slavkin H. Reforming dental health professions education: a white paper. J Dent Educ 2004;68: 1139-50.

2. American Association of Dental Schools. Dental education at the crossroads: summary. J Dent Educ 1995;59: 7-18.

3. Baum BJ, Scott J, Bicket M, Gombos G, Greenspan JS, Guo W, et al. Global challenges in research and strategic planning. Eur J Dent Educ 2002;6(Suppl 3):179-84.

4. Chambers D. Some issues in problem-based learning. J Dent Educ 1995;59:567-73.

5. Tedesco L. Issues in dental curriculum development and change. J Dent Educ 1995;59:97-132.

6. Chiodo G, Bullock WW, Creamer HR, Rosenstein DI. An application of the patient-oriented problem-solving system. J Dent Educ 1991;55:327-31.

7. Parfitt BA. A practical approach to creative teaching: an experiment. J Adv Nurs 1989;14:56-63.

8. Whipp JA, Ferguson DJ, Wells LM, Iacopino AM. Rethinking knowledge and pedagogy in dental education. $\mathrm{J}$ Dent Educ 2000;64:860-6.

9. Goldstein BH. Unconventional dentistry: Part I. Introduction. J de L'Assoc Dentaire Canadienne 2000;66(6):323-6.

10. Marinho V, Richards D, Niederman R. Variation, certainty, and change in dental education: employing evidencebased dentistry in dental education. J Dent Educ 2001;65(5):449-55.
11. American Dental Education Association. Competencies for entry into the profession of dental hygiene. J Dent Educ 2000;64(7):Appendix II.

12. Darby M, Walsh M. Introduction to the dental hygiene process. In: Darby M, Walsh M. Dental hygiene theory and practice. $2^{\text {nd }}$ ed. Philadelphia: Saunders, 2003.

13. Woodall IR. Comprehensive dental hygiene care. St. Louis: Mosby, 1993.

14. Colucciello ML. Critical thinking skills and dispositions of baccalaureate nursing students: a conceptual model for evaluation. J Pro Nurs 1997;13:236-45.

15. Grossman S, Campbell C, Riley B. Assessment of clinical decision-making ability of critical care nurses. Dimensions Crit Care Nurs 1996;15:272-9.

16. White JE, Nativio DG, Kobert SN, Engberg SJ. Content and process in clinical decision-making by nurse practitioners. J Nurs Scholarsh 1992;24:153-8.

17. Carnevali DL, Mitchell PH, Woods NF, Tanner CA. Diagnostic reasoning in nursing. Philadelphia: Lippincott, 1984.

18. Halpern D. Teaching critical thinking for transfer across domains. Am Psychol 1998;53:449-55.

19. Rane-Szostak D, Robertson JF. Issues in measuring critical thinking: meeting the challenge. J Nurs Educ 1996; 35:5-11.

20. Kempainen RR, Migeon MB, Wolf FM. Understanding our mistakes: a primer on errors in clinical reasoning. Med Teacher 2003;25(2):177-81.

21. Groves M, O'Rourke P, Alexander H. Clinical reasoning: the relative contribution of identification, interpretation and hypothesis errors to misdiagnosis. Med Teacher 2003; 25(6):621-5.

22. Schmidt HG, Norman GR, Boshuizen HP. A cognitive perspective on medical expertise: theory and implications. Acad Med 1990;65:611-21.

23. Charlin B, Tardif J, Boshuizen HP. Scripts and medical diagnostic knowledge. Acad Med 2000;75:182-90.

24. Crespo KE, Torres JE, Recio ME. Reasoning process characteristics in the diagnostic skills of beginner, competent and expert dentists. J Dent Educ 2004;68:1235-44.

25. Neistadt ME. Teaching clinical reasoning as a thinking frame. Am J Occup Ther 1998;52:221-9.

26. Miller M, Malcolm N. Critical thinking in the nursing curriculum. Nurs Health Care 1990;11:67-72.

27. Brooks KL, Shepard JM. The relationship between clinical decision-making skills in nursing and general critical thinking abilities of senior nursing students in four types of nursing programs. J Nurs Educ 1990;29:391-9.

28. Miller DA, Sadler JZ, Mohl PC. Clinical thinking in preclinical course examinations. Acad Med 1993;68:303-5.

29. Scott JN, Markert RJ. Relationship between critical thinking skills and success in preclinical courses. Acad Med 1994;69:920-4.

30. Scott JN, Markert RJ, Dunn MM. Critical thinking: change during medical school and relationship to performance in clinical clerkships. Med Educ 1998;32:14-8.

31. Chambers D. Predictive validity of instructor judgment in preclinical technique courses. J Dent Educ 1997;61: 736-40.

32. Scott A, Chase L, Lefkowitz R, Morton-Rias D, Chambers $\mathrm{C}$, Joe J, et al. A national survey of admissions criteria and processes in selected allied health professions. J Allied Health 1995;24:95-107. 
33. Conger MM, Mezza I. Fostering critical thinking in nursing students in the clinical setting. Nurse Educ 1996;21: 11-5.

34. Croen L, Reichgott M, Spencer R. A performance-based method for early identification of medical students at risk of developing academic problems. Acad Med 1991; 66:486-8.

35. Berchulc C, Wade G, Seidner K. Predicting academic achievement of undergraduate occupational therapy students: preliminary results. Occup Ther J Res 1987; 7:245-8.

36. Williams K, Glasnapp D, Tilliss T, Osborn J, Wilkens K, Mitchell S, et al. Predictive validity of critical thinking skills for initial clinical dental hygiene performance. J Dent Educ 2003;67:1180-92.

37. Scheetz JP. Predicting graduation from dental school using admissions data. J Dent Educ 1987;51:250-1.

38. Kress GC, Dogon IL. A correlational study of preadmission predictor variables and dental school performance. J Dent Educ 1981;45:207-10.

39. Walsh CM, Hardy RC. Factor structure stability of the California Critical Thinking Disposition Inventory across sex and various students' majors. Percept Mot Skills 1997;85:1211-28

40. Wingert TA. Predictors of performance in optometry school: a study at the University of Missouri-St. Louis. J Optometric Educ 1993;19:18-21.

41. Gable RK, Roberts AD, Owen SV. Affective and cognitive correlates of classroom achievement. Educ Psych Measurement 1977;37:977-86.

42. Brailovsky C, Charlin B, Beausoleil S, Cote S, Van der Vleuten C. Measurement of clinical reflective capacity early in training as a predictor of clinical reasoning performance at the end of residence: an experimental study on the script concordance test. Med Educ 2001;35(5):430-6.

43. Tanner CA, Padrick KP, Westfall VE, Putzier DJ. Diagnostic reasoning strategies of nurses and nursing students. Nurs Res 1987;36:358-63.

44. Collins A. Cognitive apprenticeship and instructional technology. In: Idol L, Jones BF, eds. Educational values and cognitive instruction: implications for reform. Hillsdale, NJ: Erlbaum, 1991.

45. Modjeski RB, Michael WB. An evaluation by a panel of psychologists of the reliability and validity of two tests of critical thinking. Educ Psych Measure 1983;43:1187-97.

46. Facione PA, Giancarlo CA, Facione NC, Gainen J. The disposition towards critical thinking. J Gen Educ 1995; 44:1-16.
47. Behar-Horenstein L, Dolan T, Courts F, Mitchell G. Cultivating critical thinking in the clinical learning environment. J Dent Educ 2000;64:610-5.

48. Chenoweth L. Facilitating the process of critical thinking for nursing. Nurse Educ Today 1998;18:281-92.

49. Adams MH, Stover LM, Whitlow JF. A longitudinal evaluation of baccalaureate nursing students' critical thinking abilities. J Nurs Educ 1999;38;139-41.

50. Facione PA, Facione NC. California Critical Thinking Skills Test: form A \& B test manual. Millbrae, CA: California Academic Press, 1998.

51. Facione PA, Facione NC, Giancarlo CA. The California Critical Thinking Disposition Inventory: test manual. Millbrae, CA: California Academic Press, 1998.

52. May BA, Edell B, Butell S, Doughty J, Langford C. Critical thinking and clinical competence: a study of their relationship in BSN seniors. J Nurs Educ 1999;38:100-10.

53. Pardue S. Decision-making skills and critical ability among associate degree, diploma, baccalaureate, and master's prepared nurses. J Nurs Educ 1987;26:354-61.

54. Fredrickson K, Mayer G. Problem-solving skills: what effect does education have? Am J Nurs 1977;77:1167-9.

55. Sorrell JM, Brown HN, Silva MC, Kohlenberg EM. Use of writing portfolios for interdisciplinary assessment of critical thinking outcomes of nursing students. Nurs Forum 1997;32:12-24.

56. Sorensen-Bowles K. Effects of critical thinking, grade point average, and college experience on the clinical judgment skills of baccalaureate nursing students. Unpublished doctoral dissertation, University of Southern California, 1997.

57. Shamian J. Effect of teaching decision analysis on student nurses' clinical intervention decision making. Res Nurs Health 1991;14:59-66.

58. Weis PA, Guyton-Simmons J. A computer simulation for teaching critical thinking skills. Nurs Educ 1998;23:10-33.

59. Haffer AG, Raingruber BJ. Discovering confidence in clinical reasoning and critical thinking development in baccalaureate nursing students. J Nurs Educ 1998;37:61-70.

60. McCarthy P, Schuster P, Zehr P, McDougal D. Evaluation of critical thinking in a baccalaureate nursing program. J Nurs Educ 1999;38:142-4.

61. Hagedorn R. Clinical decision making in familiar cases: a model of the process and implications for practice. $\mathrm{Br} \mathrm{J}$ Occup Ther 1996;59:217-22.

62. O'Neill E. An exploratory study of clinical decision making in home healthcare nursing. Home Healthcare Nurse 1996;14:363-8. 